\title{
Olifants River Bridge Widening
}

\author{
Andrew Rowan ${ }^{1}$ and Les Thomson ${ }^{1}$ \\ ${ }^{1} \mathrm{HHO}$ Consulting Engineers, Cape Town, South Africa
}

\begin{abstract}
The Olifants River Bridge B3611 carries the N11 over the Olifants River, just North of the Loskop Dam. This structure was originally built in 1979 and was recently widened as part of the South African Roads Agency Limited (SANRAL)'s upgrade to the N11. At the time of design, very little was known about the bridge as no 'As Built' drawings were available. Due to the remote locality of the structure, exploratory investigations were reserved until the construction phase. The final design solution was therefore amended during the construction phase in order to account for the reinforcement found within the structure. In addition to the heavier dead weight of the new widened deck, the bridge would be required to carry higher loads under modern loading codes. Widening works included new widened cantilevers with new reinforced concrete balustrades, tying into existing reinforcement. Strengthening for bending was provided to the main deck beams by means of longitudinal FRP plates epoxied to the soffit. Transverse pierhead strengthening using DYWIDAG bars was installed to counter increased moments, and pier strengthening using a reinforced concrete jacket was implemented to strengthen the piers. Durability concrete was specified in accordance with current SANRAL regulations and the durability performance of the concrete, even in this remote location was excellent. This paper summarises the work that was completed as part of this project.
\end{abstract}

\section{Introduction}

B3611 Olifants River Bridge was constructed in 1979 to the North of the Loskop Dam in the Mpumalanga Province of South Africa. The bridge is a seven span $151 \mathrm{~m}$ long reinforced concrete structure that carries the National Route 11 over the Olifants River. The $22 \mathrm{~m}$ spans are simply supported and rest on elastomeric rubber bearings. Cylindrical Piers are 1,5m in diameter and are founded on pad footings set into competent rock. Abutments are vertical reinforced concrete cantilever type, with return walls running parallel to the road centreline. The deck level is approximately 9-10 metres above the founding level.

While the structure was in good condition at the time of initial inspection, the required road cross section for the upgrade N11 necessitated the widening of the bridge.

\section{Preliminary Design}

Unfortunately no As-Built information was available at the time of preliminary design. As such, it was unknown what original design loads were allowed for, and what reinforcement was provided.

While investigating the structure in more detail was an option, the cost, time delay and remote location of the bridge site resulted in the designers opting for a more conservative design, which could then be rationalised and possibly reduced during the construction phase, once the structure could be more fully investigated.

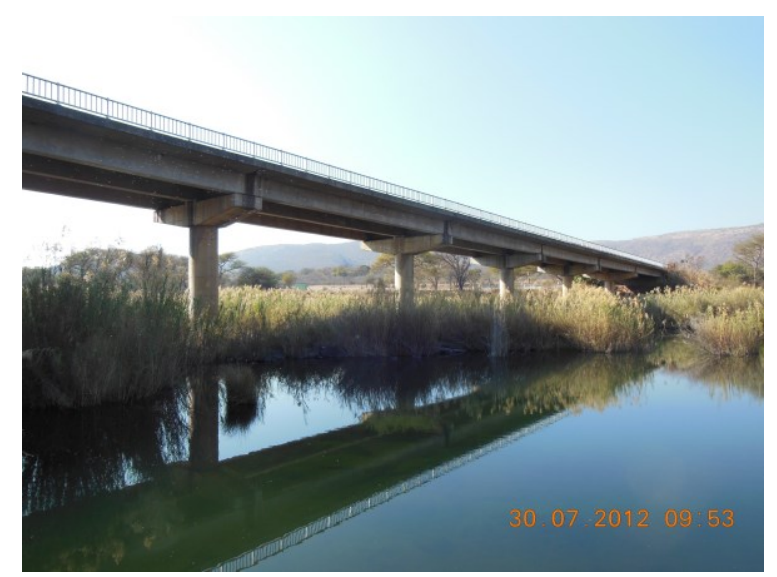

Fig. 1. B3611 Olifants River Bridge prior to Widening.

\section{Existing Bridge Condition}

An Under Bridge Inspection Unit (UBIU) vehicle was used to inspect the bridge prior to the design phase. A full inspection according to the SANRAL Bridge Management System (BMS) was performed by an accredited senior bridge inspector. Defects were rated in terms or degree, extent, relevance and urgency. It was found that in general the structure was in good condition

\footnotetext{
* Corresponding author: andrew@hho.co.za
} 
and showed little sign of damage. Some minor shear cracking in the longitudinal beams was present. Expansion joints needed replacement and other minor improvements (eg painting handrails, cleaning drainage scupper and replacing manhole covers) were noted as being required.

\section{Original Design / As Built Information}

As the structure was constructed in 1979, it was assumed that the original design had adopted the BS 153 (1954) loading system in its structural analysis. This called for a uniformly distributed linear traffic load of 2200 pounds per foot to be applied along with a single heavy axle line load of 2700 pounds per foot. By comparison, current loading requirements prescribed by TMH7 Parts 1 and 2 have requirements of up to $20-60 \%$ higher that the BS 153 loading code. The live loads that the structure would need to handle are therefore higher. In addition to this, the dead loads from the widened cantilevers are increased.

The consequence of this is that even if the original design was conservative, the new loads (live and dead) would require strengthening to the majority of the structure.

\section{Deck Widening}

It transpired early on in the design phase that the client's requirements for a 'full' upgraded geometric cross section for the entire N11 route would require several structural widenings along the length of the project. This also presented an opportunity to upgrade the existing balustrade (Steel balustrade) to a SANRAL standard F Shape Parapet capable of resisting current design impact loads.

\section{Cantilevers}

The existing 1,5m cantilevers were demolished by means of hydraulic impact hammers, while retaining the reinforcement to be lapped onto the new longer cantilever reinforcement (see section 13). Where moments were increased due to longer cantilevers, increased traffic and impact loads, this was accounted for by increasing the depth of the cantilevered section. The original proposal (later revised) was to include additional main reinforcement that would be tied into the remaining deck, anchored into recesses cut in to the top slab of the deck. There were several questions at the time of design regarding the amount of reinforcement present in the existing section, the configuration, the cover depths, even the material strength of the reinforcement itself was assumed. These would be later confirmed in the construction phase, but a conservative approach was taken in the design phase.

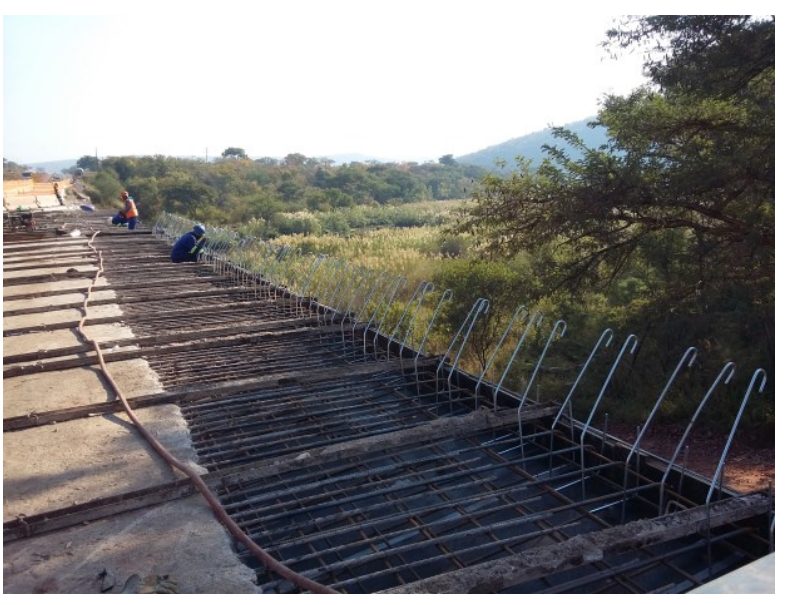

Fig. 2. Reinforcement preparation prior to casting on new cantilevers.

\section{Longitudinal Beams}

As the amount of reinforcement in the existing longitudinal beams was unknown, any additional loads due to increased dead weight or additional design live loading was accounted for by the addition of longitudinal steel plates up to $12 \mathrm{~mm}$ thick. These would have been epoxied onto the underside of each of the longitudinal beams. The external beams called for a $12 \mathrm{~mm}$ plate and the internal beams called for a $7 \mathrm{~mm}$ plate.

\section{Shear Strengthening}

Similarly the longitudinal beams were also given strengthening for increased shear forces by means of $5 \mathrm{~mm}$ vertical shear plates epoxied on either side of the beams at varying centres. These were intended to be anchored vertically through the deck and bolted into place temporarily during the setting time of the epoxy used to adhere the plates to the beams.

\section{Pierhead Strengthening}

The pierhead required strengthening in the form of external prestressing. $3 \times 40 \mathrm{~mm}$ diameter DYWIDAG threaded bars were used on either side of the pierhead to counter the additional moments. These bars were then encased in concrete.

\section{Pier Jacketing}

The additional moments induced into the piers, especially during construction stages and for earthquake design, required that the $1800 \mathrm{~mm}$ dimeter cylindrical piers be strengthened. Additional strengthening works in the form of column wrapping with FRP sheets was investigated but was not preferred by the client for reasons of durability and long term robustness due to potential scour in the river under flood conditions. The final solution adopted was a simple $150 \mathrm{~mm}$ reinforced concrete jacketing for the full height if the pier. Anchor 
bars were drilled into the pier to improve interaction and bond between old and new concretes.

\section{Exploratory investigations}

As soon as the contractor was established on site, we were then in a position to confirm reinforcement amounts in the various elements. Specific locations were identified and scabbled to expose outer reinforcement. This confirmed both the size and spacing of reinforcement for key bridge elements.

\section{Confirmation of reinforcement strength}

It was also necessary to confirm the strength of the reinforcement, as it was unclear what material properties were present with the existing rebar. Tests concluded that the reinforcement was of an equivalent yield strength to our current day high yield strength reinforcement (i.e $450 \mathrm{MPa} \mathrm{Y}$ bars).

\section{Revised design}

The tests and exploratory investigations now left the engineers in a position rationalise/reduce the original design. The requirement for additional shear reinforcement was removed since large amounts or shear reinforcement was found in the longitudinal beams. The amount of longitudinal reinforcement required in the form of plates was left as originally specified.

\section{These things happen - Cantilever reinforcement accidentally removed}

The detail proposed for extending the existing cantilevers including utilising the existing reinforcement in the cantilevers, and lapping new reinforcement onto these bars (once they were exposed). Unfortunately an incident involving a misunderstanding on the site instruction saw the first span's reinforcement completely removed, which left a challenge as to how the new reinforcement would be adequately anchored into the existing deck. The implemented solution was to return to the original proposal of using longer heavier bars located in recesses, which we then bent through 90 degrees and anchored vertically into the deck. The anchor protrudes though the thickness of the beck and the exposed bar is then locked off with a plate and bolt arrangement. All exposed steel is then given corrosion protection in the form of multiple zinc rich barrier coatings.

\section{Concrete Durability Performance}

"Durability' concrete was specified in the tender documents for this structure, and this required certain performance criteria for Oxygen Permeability Tests, Water Sorptivity Tests and Chloride Conductivity. For each of these tests, the highest categorization of performance was achieved.

\section{$16 \quad$ Longitudinal Strengthening alternative}

The original specification for the longitudinal plates required for beam strengthening called for $12 \mathrm{~mm}$ thick plate with a width of $570 \mathrm{~mm}$ and length of up to $20 \mathrm{~m}$. The weight of this plate would be in the order of 1 tonne, and the application of the plates at height over a sensitive area proved to be a challenge on site. The contractor proposed an alternative of using FRP bands with an equivalent strength. This was accepted by the client, and was implemented on site.

\section{Deck vibrations/ limiting traffic}

During casting of the new cantilevered section, concerns were raised by the contractor of the vibrations induced by vehicle traffic on the bridge, and whether or not this would have a negative effect on the curing and strength gain of the new concrete. In order to mitigate this, traffic was limited on the deck for the first few days after each cast.

\section{Balustrades}

The original steel balustrades were removed, and replaced with SANRAL standard F Shape Parapets design to withstand $100 \mathrm{kN}$ impact loads. An updated endblock shape was also required, in line with the latest client standards.

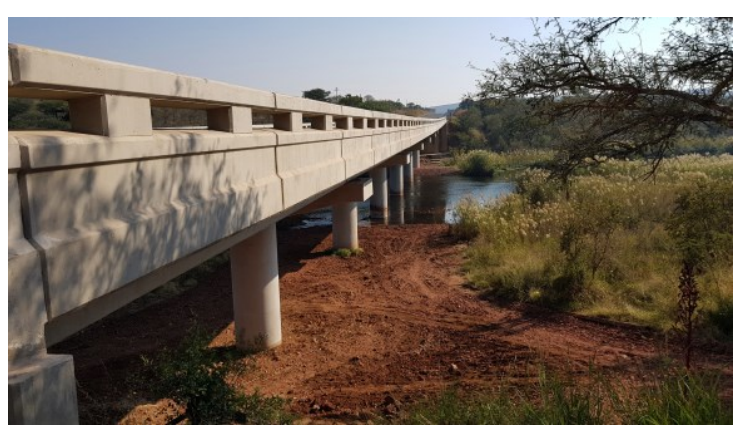

Fig. 3. Finished structure showing new balustrades.

\section{Joints}

The existing concrete nosing joints were replaced by asphaltic plug joints.

\section{Conclusion}

This paper covered the successful design and construction of a bridge widening in the Mpumalanga Province of South Africa. Innovative designs and creative responses to various challenges resulted in an attractive and structurally sound solution for the client. 
The project was completed on time and within budget, and is a testimony to the South African 'can do' approach to life.

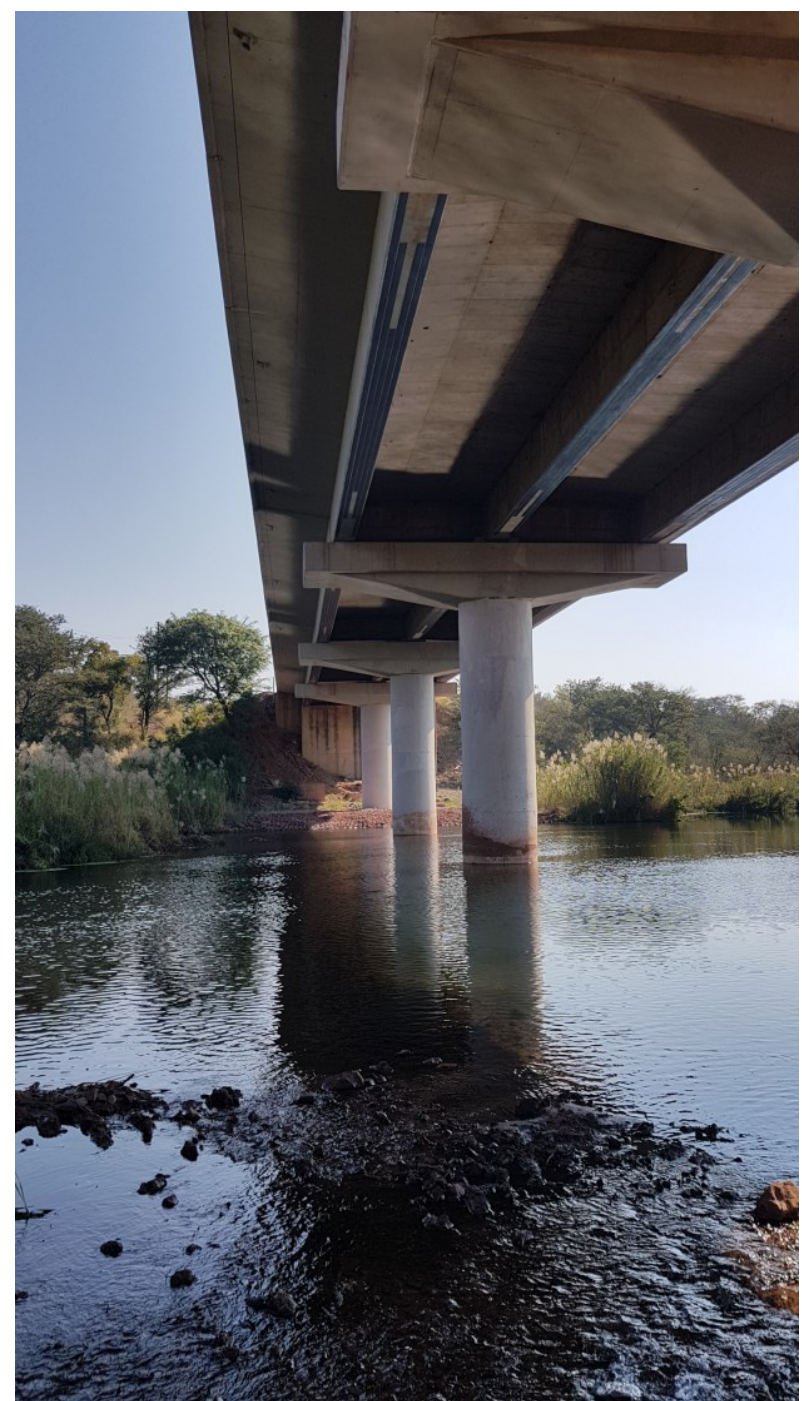

Fig. 4. Underside of finished widening showing elegant beam strengthening and pierhead external prestressing 